\title{
Reduced Graphene Oxide-Polycarbonate Electrodes on Different Supports for Symmetric Supercapacitors
}

\author{
Olena Okhay ${ }^{1, *(\mathbb{D}}$, Alexandre Cunha Bastos ${ }^{2}\left(\mathbb{D}\right.$, Kateryna Andreeva ${ }^{3}$, Sampo Tuukkanen ${ }^{4}$ \\ and Alexander Tkach ${ }^{2}$ (D) \\ 1 TEMA-Centre for Mechanical Technology and Automation, Department of Mechanical Engineering, \\ University of Aveiro, 3810-193 Aveiro, Portugal \\ 2 CICECO-Aveiro Institute of Materials, Department of Materials and Ceramic Engineering, \\ University of Aveiro, 3810-193 Aveiro, Portugal; acbastos@ua.pt (A.C.B.); atkach@ua.pt (A.T.) \\ 3 V. Lashkaryov Institute of Semiconductor Physics at NAS of Ukraine, 03028 Kyiv, Ukraine; \\ ev_andreeva322@ukr.net \\ 4 Faculty of Medicine and Health Technology, Tampere University, FI-33101 Tampere, Finland; \\ sampo.tuukkanen@gmail.com \\ * Correspondence: olena@ua.pt
}

check for updates

Citation: Okhay, O.; Bastos, A.C.; Andreeva, K.; Tuukkanen, S.; Tkach, A. Reduced Graphene Oxide-Polycarbonate Electrodes on Different Supports for Symmetric Supercapacitors. C 2022, 8, 12. https://doi.org/10.3390/c8010012

Academic Editors:

Camélia Matei Ghimbeu and Oluwafunmilola Ola

Received: 13 December 2021

Accepted: 31 January 2022

Published: 2 February 2022

Publisher's Note: MDPI stays neutral with regard to jurisdictional claims in published maps and institutional affiliations.

Copyright: (C) 2022 by the authors. Licensee MDPI, Basel, Switzerland. This article is an open access article distributed under the terms and conditions of the Creative Commons Attribution (CC BY) license (https:// creativecommons.org/licenses/by/ $4.0 /)$.

\begin{abstract}
Electrode materials for electrochemical capacitors or supercapacitors (SCs) are widely studied, as they are needed for the development of energy storage devices in electrical vehicles and flexible electronics. In the current work, a self-supported paper of reduced graphene oxide (rGO) with polycarbonate (PC) (as rGO-PC composite) was prepared by simple vacuum filtration and lowtemperature annealing. rGO-PC as a freestanding single electrode was studied in a three-electrode system and presented a capacitive energy storage mechanism. To fabricate SCs based on rGO-PC, flexible polyethylene terephthalate (PET) with layers of both $\mathrm{Cu}$ tape (Cu tape) and carbon tape (C tape) (PET/Cu/C), as well as PET covered by graphene ink (PET/GrI), were used as supports. Fabricated flexible symmetric SCs have shown similar behavior with a higher areal capacitance value than that on PET/Cu/C substrate.
\end{abstract}

Keywords: reduced graphene oxide; polymer; vacuum filtration; freestanding electrode; flexible supercapacitors

\section{Introduction}

Graphitic carbon monolayers were observed and studied more than several decades ago. At the beginning, in 1859, Sir Benjamin Collins Brodie described the highly lamellar structure of thermally reduced graphite oxide [1]. In 1918, the powder diffraction technique was used to study the structure of graphite, and graphite oxide "paper" was described by Kohlschütter and Haenni [2]. Later, the theory of graphene was prepared and published by Wallace in 1947 [3]. In the following year, Ruess and Vogt first showed just arrived electron microscopy images of few-layer graphite, accompanied by further observation of single graphene layers [4]. In 1986, Boehm et al. referred to a single layer of graphite or a thin layer of $\mathrm{sp}^{2}$ hybridized carbon atoms arranged in a honeycomb lattice as graphene [5]. However, it was only in 2004 that isolated graphene was reported to be obtained using the simple scotch tape method [6]. The subsequent discoveries of its unusual properties have led to an extraordinary interest amongst researchers across almost all scientific disciplines $[7,8]$. For instance, graphene has a high mechanical strength and a large specific surface area $\left(2630 \mathrm{~m}^{2} / \mathrm{g}\right.$ [9]), which makes it an ideal electrode material for energy storage devices.

Graphene oxide (GO) is a graphene-derived material that includes oxygen functional groups and, thus, has properties rather different from those of graphene. By reduction, these functional groups are removed resulting in reduced graphene oxide (rGO), which is a graphene-related material [10] that can be obtained in a much larger amount by easier 
ways than a monolayer of graphene. GO can be reduced by various techniques, including chemical and thermal treatments, although the former method typically requires the use of hazardous chemicals. Thus, the thermal reduction technique is the most preferred, being often used to significantly increase the electrical conductivity of rGO material [11]. Moreover, the specific surface area also increases with the reduction temperature but only up to $350{ }^{\circ} \mathrm{C}$ [12]. At the same time, the removal of functional groups at a high temperature creates defects in the carbon lattice plane, and the final properties of rGO can significantly depend on the annealing temperature [13]. The lowering of the defect concentration, as well as a significant ( two times) decrease in the lattice $\mathrm{d}$-spacing, was reported to start at about $200^{\circ} \mathrm{C}$ for freestanding GO papers prepared by vacuum filtration [14]. Moreover, freestanding rGO paper heat treated at $200^{\circ} \mathrm{C}$ can also show a higher gravimetric or areal capacitance than rGO obtained at much higher temperatures [15].

Although rGO cannot show the same ideal structure as graphene, it can present a low enough sheet resistance from $\sim 1000 \Omega / \square$ to $<200 \Omega / \square$ [16] and chemical and thermal stability while not being as expensive as graphene. Thus, rGO is a highly acceptable material to be used in a large amount of sensors, environmental or catalytic applications as well as biological and optoelectronic devices [17]. rGO is especially intensively studied for application in energy storage devices, particularly in supercapacitors (SCs) due to its high enough specific capacitance of $\sim 250 \mathrm{~F} / \mathrm{g}$ [18] and high specific surface area (SSA) of $\sim 1520 \mathrm{~m}^{2} / \mathrm{g}$ [19-22], although a high SSA does not guarantee the rising specific capacitance [23-26]. At the same time, the applications of rGO on flexible substrates are particularly promising [27].

Different methods have been employed for the preparation of rGO electrodes, including suspension-based vacuum filtration; electrophoretic deposition as well as that at microwaves; fiber injection; transferring; and powder-/aerogel-/hydrogel-based deposition by screen printing, gluing, dropping, covering, etc. [28,29]. For example, layer-by-layer (LBL) deposition and solution casting methods present advantages when preparing ultrathin hybrid films with a controllable thickness. However, the LBL technique lacks practical significance for the preparation of thick papers because of the complicated, time-consuming assembly process. Solution casting is another simple and easy method to assemble thin films because it only needs the evaporation of moisture from the cast dispersion on a substrate. The vacuum filtration method involves simple filtration of graphene oxide or hybrid dispersions through a microporous filter membrane with the aid of vacuum pumping, allowing the deposition of highly aligned graphene sheets [30]. Thus, vacuum filtration is also one of the easiest ways to prepare electrodes [31], although the following electrochemical analysis of these materials in supercapacitors can be difficult without additional support.

Polycarbonate (PC) is a thermoplastic polymer with enhanced thermal stability [32,33] and mechanical stiffness [34], and it is used in a wide range of applications [35], such as photonics [36], automotive and aeronautic industries [33,37]. At the same time, the composites of PC with graphene have also been widely studied as promising materials for 3D printing [38], photoactuators [39] and energy storage applications [40]. In addition, based on the studied electrochemical properties of PC [41], it can be used as a supercapacitor membrane [42,43] or as a polymer electrolyte [44,45]. It was also reported to be used after chemical recycling as activated carbon in supercapacitor electrodes [46].

However, to date, no direct use of PC alone or in a composite with rGO as an SC electrode material has been reported to the best of our knowledge. Therefore, freestanding rGO-polycarbonate paper discs were prepared by vacuum filtration and investigated here as freestanding electrodes. In addition, they were assembled onto two different substrates and encapsulated in supercapacitors for electrochemical test analysis and comparison. For that, two substrates were fast and simply prepared in the laboratory from such available and inexpensive materials as flexible polyethylene terephthalate (PET), $\mathrm{Cu}$ tape $(\mathrm{Cu})$, carbon tape (C) and graphene ink (GrI). 


\section{Materials and Methods}

\subsection{Preparation of Graphene Oxide Solution}

A light brown graphene oxide (GO) solution $(2 \mathrm{~g}$ per $1 \mathrm{~L}$ ) was prepared based on the Hummer method. Commercially available natural flake graphite, sulfuric acid (99.99\%), potassium permanganate $(99 \%)$, hydrogen peroxide $\left(30 \mathrm{wt} \%\right.$ in $\mathrm{H}_{2} \mathrm{O}$ ) and hydrochloric acid $(37 \%)$ were used as received from Sigma-Aldrich Chemie GmbH, Taufkirchen, Germany. All aqueous solutions were prepared with deionized distilled water. GO was synthesized using the following process: $50 \mathrm{~mL}$ of $98 \%$ sulfuric acid was placed in a $250 \mathrm{~mL}$ chemical glass flask provided with a magnetic stirrer and fixed in a water bath with a small amount of added ice. Then, $2 \mathrm{~g}$ of graphite powder was added to the acid. After stirring for a few minutes, $6 \mathrm{~g}$ of dry potassium permanganate was added to the reactant mixture. Later, the mixture was heated to $35^{\circ} \mathrm{C}$ and diluted with $100 \mathrm{~mL}$ of water for $20 \mathrm{~min}$. The diluted mixture was held for $30 \mathrm{~min}$ at a temperature of $70{ }^{\circ} \mathrm{C}$, followed by addition of $100 \mathrm{~mL}$ of water and $10 \mathrm{~mL}$ of $3 \%$ hydrogen peroxide. Immediately thereafter, the mixture was passed through a paper filter under evacuation. The filtered-out material was mixed with $500 \mathrm{~mL}$ of distilled water using a magnetic stirrer for $10 \mathrm{~min}$. The GO fraction was separated from the reaction products using a centrifuge. The final product was a light brown GO solution, which did not reveal any signs of settling under further centrifuging for a prolonged time.

\subsection{Preparation of rGO-PC Freestanding Electrode}

The freestanding rGO-PC paper was obtained by a process similar to that described in our previous work [47] with addition of polycarbonate ( $P C, \mathrm{C}_{15} \mathrm{H}_{16} \mathrm{O}_{2}$ ) (Sigma-Aldrich Chemie $\mathrm{GmbH}$, Taufkirchen, Germany). Briefly, $0.5 \mathrm{~g}$ of PC was dissolved with $30 \mathrm{~mL}$ of dichloromethane $\left(\mathrm{CH}_{2} \mathrm{Cl}_{2}\right.$, Sigma-Aldrich Chemie $\mathrm{GmbH}$, Taufkirchen, Germany) and mixed with GO solution at a weight ratio of 1:2 (PC:GO). Homogeneous solution was poured into a glass funnel (see Figure 1a) and filtered by laboratory vacuum pump with Millipore membrane filters (pore size $=0.45 \mu \mathrm{m}$, Merck Milipore, Darmstadt, Germany). Obtained wet samples (see Figure $1 b$ ) were dried at room temperature for 1 day, removed from the membrane as freestanding papers and thermally treated at $180{ }^{\circ} \mathrm{C}$ in vacuum oven (Vacutherm, Thermo Fischer Scientific GmbH, Dreieich, Germany) for $1 \mathrm{~h}$, resulting in samples with areal loading of about $0.7 \mathrm{mg} / \mathrm{cm}^{2}$, referred to here as rGO-PC. Based on the geometrical and theoretical density values, and due to the fact that papers are freestanding, their porosity was assessed as $91 \%$. We assessed the porosity value based on the assumption of the presence of the nominal polymer concentration in the analyzed electrode materials.


Figure 1. Digital photographs of glass funnel for vacuum filtration (a), vet sample after vacuum filtration of solution through PVDF membrane (b), rGO-PC paper connected to electrode (c) and home-made electrochemical cell used for the measurements of the single electrode in electrolyte (d). 


\subsection{Preparation of $r G O-P C$-Based Supercapacitors}

Two supercapacitors were prepared by laminating two electrodes together with an electrolyte and separator in between according to the scheme shown in Figure 2a. For one of them, PET (Melinex ST506 from Dupont Teijin Films, Dumfries, UK) only covered by adhesive $\mathrm{Cu}$ tape $(\mathrm{Cu})$ (Mouser Electronics, Barcelona, Spain) and conductive carbon double-sided tape (C) (Nissin EM Co Ltd., Tokyo, Japan) using a layer-by-layer simple method resulted in PET/Cu/C substrate. rGO-PC freestanding disks were attached to the top $\mathrm{C}$ tape (see Figure 2a, right). Two equal PET/Cu/C/rGO-PC electrodes were used to prepare symmetric SC with a TF4050 paper separator (Nippon Kodoshi Corporation, Kochi, Japan) and $1 \mathrm{M} \mathrm{NaCl}$ aqueous electrolyte. The high electrolyte concentration was selected to ensure an excess of ions such that the risk of electrolyte starvation and additional internal resistance was removed [48]. The electrodes and separator were sandwiched together with the electrolyte and sealed with an adhesive film (UPM Raflatac, Tampere, Finland). The assembly was carried out with the electrodes at $90^{\circ}$ angle with respect to each other, forming a square-shaped supercapacitor at the electrode overlap area as shown in Figure $2 b$. For the electrodes of the second SC, the conductive graphite ink (GrI) (Electrodag PC407C, Acheson Industries Ltd., Cattedown, UK) was blade coated on top of the PET substrate using the mask for patterning and was subsequently cured at $120^{\circ} \mathrm{C}$ for $5 \mathrm{~min}$, which resulted in PET/GrI substrate. rGO-PC disk paper was placed onto Gr-ink. Two PET/GrI/rGO-PC electrodes were assembled in full device (see Figure 2c) by the method described above and checked for flexibility (see Figure 2d).


Figure 2. The structure of the assembled supercapacitor (a) and digital photographs of SCs on PET with $\mathrm{Cu}$ and $\mathrm{C}$ tapes (b) and PET with graphite ink (c). Image of the fabricated SC presenting its flexibility (d).

\subsection{Characterization}

X-ray diffraction (XRD) profiles of the studied samples were collected at room temperature in a continuous scanning mode (step $0.02^{\circ}$ and time $10 \mathrm{~s}$ ) using a diffractometer (SmartLab, Rigaku, Tokyo, Japan) in the $2 \theta$ range from $5^{\circ}$ to $50^{\circ}$. Morphology of the studied samples was analyzed by scanning electron microscope (SEM, SU70, Hitachi, Tokyo, Japan) under $15 \mathrm{kV}$ acceleration voltage. Current-voltage (I-V) characteristics were measured by the four-point method in a van der Pauw configuration using a home-made cell. The singleelectrode tests were performed with an AUTOLAB PGSTAT 302N potentiostat (Metrohm AG, Herisau, Switzerland) in a home-made electrochemical cell with the materials to be tested as a working electrode, a platinum wire as a counter electrode and a silver I silver sulphate $\left(\mathrm{K}_{2} \mathrm{SO}_{4}\right)$ electrode as a reference $\left(\mathrm{E}_{\mathrm{Ag}|\mathrm{Ag} 2 \mathrm{SO} 4| \mathrm{K} 2 \mathrm{SO} 4 \text { sat }}=0.444 \mathrm{~V}\right.$ vs. saturated calomel electrode (SCE) and $0.70 \mathrm{~V}$ vs. normal hydrogen electrode (NHE) at $22^{\circ} \mathrm{C}$ ). For the electrochemical characterization of the single electrode, a piece of the freestanding rGO-PC paper was directly connected to electrical cable as shown in Figure 1c and immersed in electrolyte in the home-made three-electrode cell presented in Figure 1d.

The supercapacitor properties were measured using a Zennium Electrochemical Workstation (Zahner Elektrik $\mathrm{GmbH}$, Kronach, Germany) in a two-electrode configuration. Cyclic voltammetry (CV) from 0 to $0.9 \mathrm{~V}$ was used to obtain a qualitative measure of the supercapacitors. The voltage sweep rate was $100 \mathrm{mV} / \mathrm{s}$. For the testing of supercapacitors, $1 \mathrm{M} \mathrm{NaCl}$ electrolyte was used. Galvanostatic charging/discharging (GCD) measurements 
were performed according to international standard IEC 62391-1:2006, Class 3 [49]. The supercapacitors were charged to $0.9 \mathrm{~V}$ in $1 \mathrm{~min}$ and held at this potential for $5 \mathrm{~min}$.

\section{Results and Discussion}

\subsection{Structural Characterization of Freestanding rGO-PC Paper}

The XRD profile of the vacuum-filtrated rGO-PC freestanding paper is presented in Figure 3, together with the data for the GO, bare rGO paper prepared by the same process and bare polycarbonate film obtained from the corresponding solution on glass substrate for comparison. The strong peak at $\sim 10.4^{\circ}$, which is characteristic for GO, is shown in Figure 3a,b to disappear after vacuum annealing at $180^{\circ} \mathrm{C}$, while a broad rGO peak at $\sim 24^{\circ}$ appeared. The final composite XRD pattern includes both weak rGO response of rGO shown in Figure $3 b$ and dominant response of PC shown in Figure $3 c$ without any extra reflections as seen in Figure $3 \mathrm{~d}$. The morphology of the rGO-PC film in the plane-view SEM image is presented in Figure 3e, revealing that the components are mixed. According to the cross-section SEM micrograph shown in Figure 3f, the thickness of the composite paper is $7 \pm 1 \mu \mathrm{m}$.

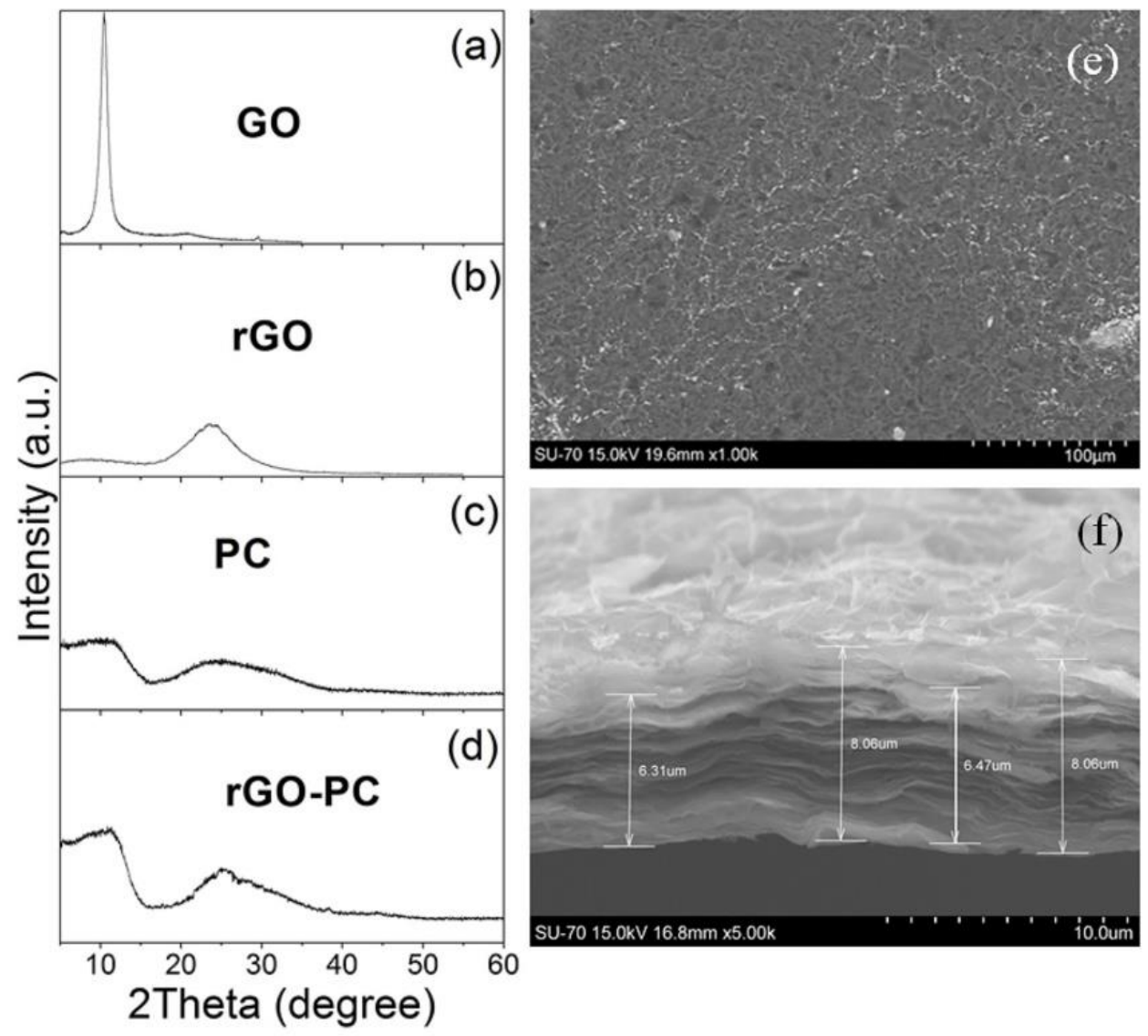

Figure 3. XRD profiles of GO (a), rGO after heat treatment at $180{ }^{\circ} \mathrm{C}(\mathbf{b}), \mathrm{PC}$ film on glass substrate (c) and rGO-PC freestanding paper prepared by vacuum filtration (d). SEM images of plan view (e) and cross-section (f) of rGO-PC paper.

\subsection{Electrochemical Characterization of Single Electrode}

Before the electrochemical characterization, the I-V test was carried out on the paper as shown in Figure 4. Semimetal electrical behavior can be seen there. A difference of several orders of magnitude (from $\mu \mathrm{A}$ to $\mathrm{A}$ ) can be found between the current values for GO (see inset of Figure 4) and rGO-PC (see Figure 4). In addition, $33 \pm 3 \Omega$ resistance was obtained with a digital multimeter when two probes were spaced at a $1 \mathrm{~cm}$ distance, 
which is low enough for electrical contact during the proposed measurements without additional support.

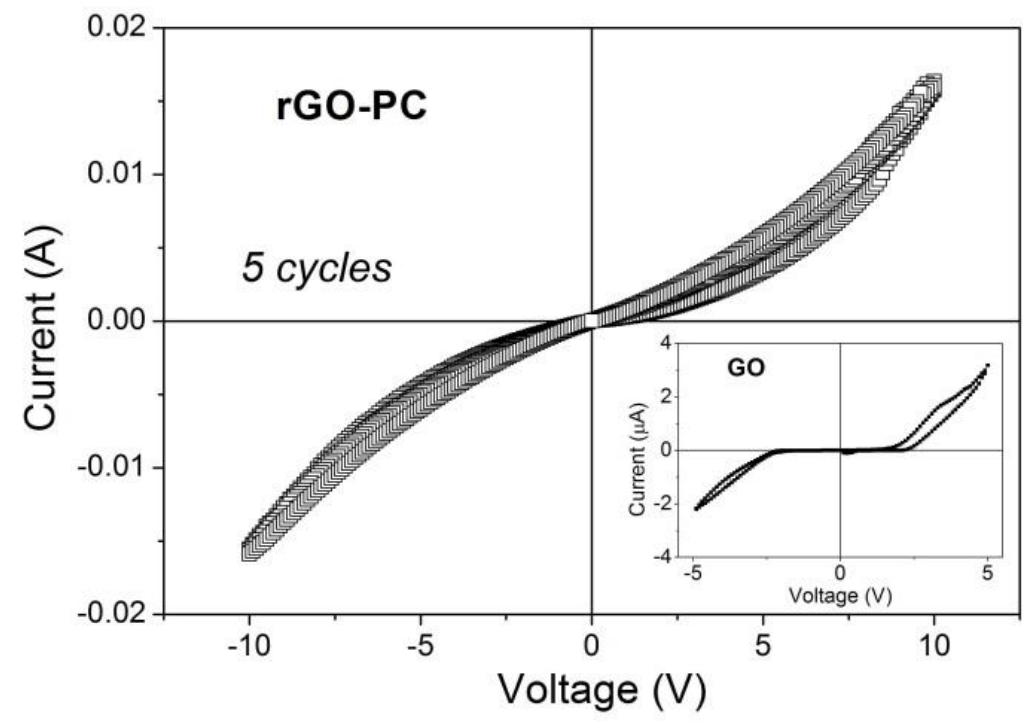

Figure 4. I-V plot of rGO-PC freestanding paper at 5 cycling measurements. Inset shows I-V of GO paper.

For the electrochemical characterization of the single electrode, rGO-PC freestanding paper was prepared as described in the Materials and Methods Section and shown in Figure 1. The self-supported rGO-PC electrode was electrochemically studied at different scan rates from 5 to $100 \mathrm{mV} / \mathrm{s}$. Figure 5 a shows the $\mathrm{CV}$ curves of the not ideal but quasi-rectangular shape without distinct peaks even at the highest scan rate of $100 \mathrm{mV} / \mathrm{s}$, suggesting the absence of obvious pseudo-capacitive contribution due to oxidation and reduction but a strong capacitive energy storage mechanism typical for an electric doublelayer capacitor (EDLC). The current change with the scan rate in the CV curve follows the power law shown in Equation (1) [50]:

$$
I=a \times v^{b}
$$


Figure 5. CV of single rGO-PC electrode measured at different scan rates (a) and calculated areal capacitances (inset). Nyquist plot of single rGO-PC electrode (b) and corresponding Bode plot (inset).

Here, $i$ is the response current at $0.1 \mathrm{~V}, v$ is the scan rate, and $a$ and $b$ are the variable parameters. The capacitive origin of the energy storage is attributed to the parameter $b$ value deduced from the $\log (i)$ vs. $\log (v)$ plot close to 1 , while battery-type behavior is associated with its value close to 0.5 . In this way, parameter $b$ was calculated from $\mathrm{CV}$ in 
Figure 5 a (as $\log (i)$ vs. $\log (v)$ plot) and found to be higher than 0.8 , which supported an EDLC type of storage in the freestanding rGO-PC electrode $[51,52]$.

The areal capacitance of the single rGO-PC electrode $C_{a}$ can be calculated from $\mathrm{CV}$ by Equation (2):

$$
C_{a}=\frac{1}{A \times v \times\left(V_{2}-V_{1}\right)} \int_{V_{1}}^{V_{2}} I(V) d V,
$$

where $A$ is the area of the electrode material; $v$ is the potential scan rate; $V_{2}-V_{1}$ is the potential window; and $I(V)$ is the response current at voltage $V$ under $C V$ operation. As can be seen from Figure 1c, the studied material is slightly brittle, and some difficulties appeared during the connection of the material as the working electrode. The area of the electrode was also not easy to determine; however, it was calculated according to the graph paper (also shown in photo of Figure 1c). According to Equation (2), the areal capacitance from CV for the rGO-PC electrode was calculated as $\sim 7.5,3.4$ and $3.1 \mathrm{mF} / \mathrm{cm}^{2}$ at 5,50 and $100 \mathrm{mV} / \mathrm{s}$, respectively (see inset of Figure 5a).

In addition, the freestanding rGO-PC was studied by electrochemical impedance spectroscopy (EIS), and the obtained results are presented in Figure $5 \mathrm{~b}$ as Nyquist plots. The Nyquist plot basically contains two major impedance components: $Z$ ' exhibits the resistive and $Z^{\prime \prime}$ shows the capacitive and/or inductive behavior of the electrode. The slope of the obtained results is almost but not perfectly vertical, which also supports the capacitive energy storage in the studied material [50]. The absence of a perfect vertical impedance line for the electrode could be because of some technical reason, such as penetration of the electrical signal and diffusion of ions in the deep inner parts of the rGO-PC electrodes. A slight and slow response to the electrical signal is also due to the oxygen functionalities, which, on the one hand, increase the resistivity of the electrode but, on the other hand, promote a faster diffusion of ions. The phase angle of the rGO-PC electrode is seen from the Bode plot, shown in the inset of Figure $5 \mathrm{~b}$ to be close to $-80^{\circ}$, which can indicate non-ideal capacitor behavior $[53,54]$. The characteristic frequency $f_{0}$ for a phase angle of $-45^{\circ}$ is $193 \mathrm{~Hz}$. This frequency marks the point at which the resistive and capacitive impedances are equal. The corresponding time constant $t_{0}=1 / f_{0}$ equals $0.005 \mathrm{~s}$, meaning that the studied material has a low frequency response (slow ion transport rate and high enough electrical resistance).

\subsection{Electrochemical Characterization of Symmetric SC on Substrates}

Furthermore, the prepared rGO-PC papers were assembled onto two PET-based supports to fabricate flexible SCs, and full-cell devices were electrochemically characterized. Two rGO-PC-based supercapacitors on the PET/Cu/C and PET/GrI substrates were prepared by laminating two electrodes together with an electrolyte and separator in between according to the scheme shown in the Materials and Methods Section. The supercapacitors were characterized by CV and GCD in an operating voltage window from 0 to $+0.9 \mathrm{~V}$ in a two-electrode cell configuration to demonstrate the applicability of the facile preparation method for composite devices on flexible supports. Although the freestanding rGO-PC electrode was characterized with CV in a three-electrode cell to obtain a qualitative view of the device properties, the use of a two-electrode cell configuration should lead to more realistic results, predicting the performance of the materials in an actual application.

The CV curves for rGO-PC on PET/Cu/C and on PET/GrI are shown in Figure 6a. The CV curves for both SCs are not ideally rectangular, indicating also that the material charges and discharges quickly and efficiently. The CV of the SC made on PET/GrI is more rectangular, but its area, as well as corresponding capacitance, is smaller than that of the SC using PET/Cu/C as a support for rGO-PC. The specific capacitance of the full SC was calculated from CV using Equation (3):

$$
C_{a \text { total }}=\frac{1}{2 \times A \times v \times\left(V_{2}-V_{1}\right)} \int_{V_{1}}^{V_{2}} I(V) d V,
$$


where $A$ is the work area of the electrodes $\left(1 \mathrm{~cm}^{2}\right), v$ is the scan rate, $\int I(V) d t$ is the integral area of the positive and negative sweeps of the $\mathrm{CV}$ curve, and $V_{1}$ and $V_{2}$ represent the voltage window of the charge (from 0 to $+0.9 \mathrm{~V}$ ).
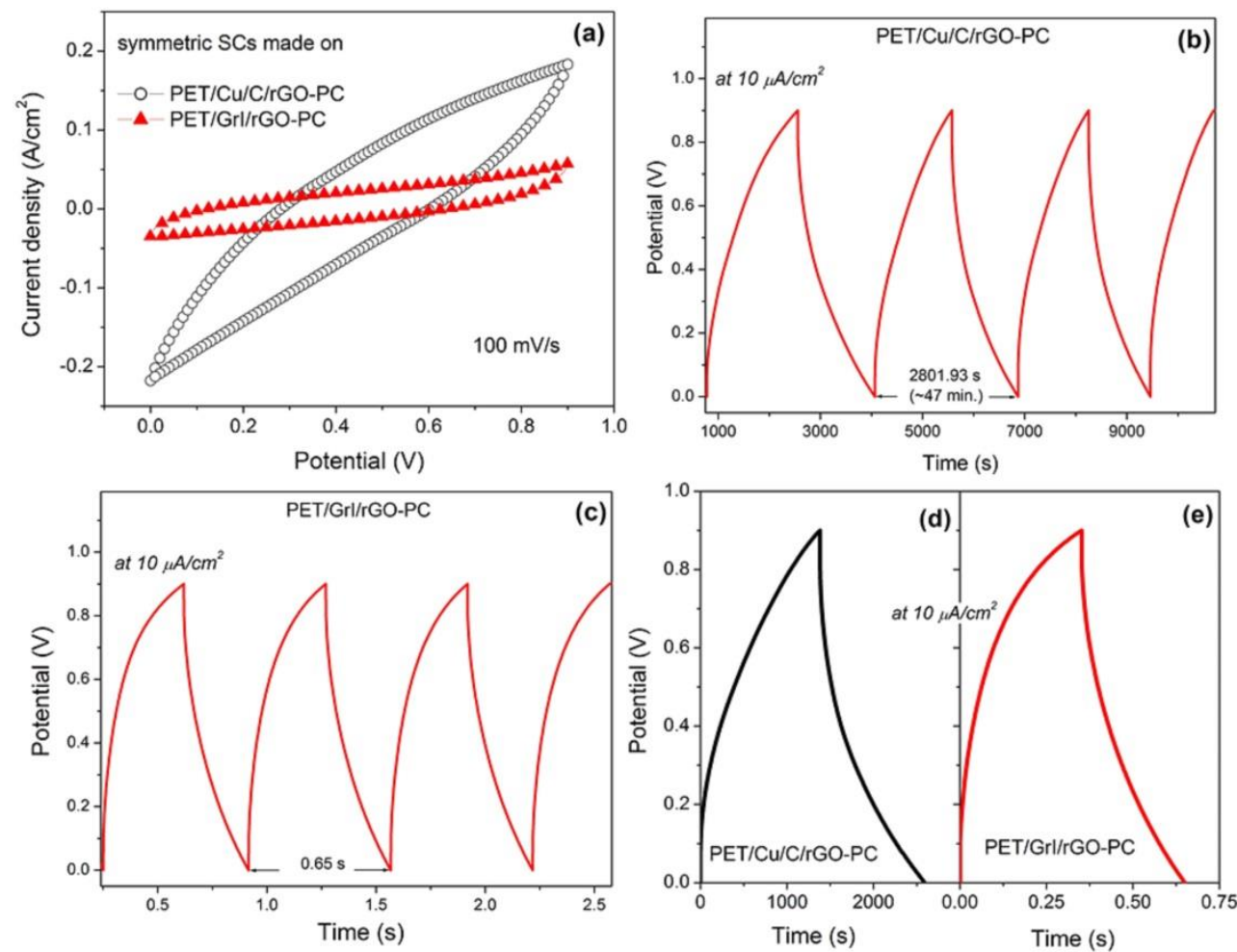

Figure 6. $\mathrm{CV}$ measured at $100 \mathrm{mV} / \mathrm{s}$ on symmetric supercapacitors made of rGO-PC active material assembled on PET with $\mathrm{Cu}$ and $\mathrm{C}$ tapes (open symbols) and PET with graphite ink (solid symbols) (a). GCD measured at $10 \mu \mathrm{A} / \mathrm{cm}^{2}$ on SC made of rGO-PC active material assembled on PET with $\mathrm{Cu}$ and $\mathrm{C}$ tapes $(\mathbf{b})$ and PET with graphite ink (c). Comparative figure of single GCD curves at $10 \mu \mathrm{A} / \mathrm{cm}^{2}$ for both SCs (d,e).

Moreover, the more precise areal capacitance of the full SC was calculated from the GCD curves (Figure 6b-e) using Equation (4):

$$
C_{a \text { total }}=\frac{2 \cdot I}{2 \times A \cdot(\Delta V)^{2}} \int_{t\left(V_{\max }\right)}^{t\left(V_{\min }\right)} V(t) d t,
$$

where $\int V(t) d t$ is the integral area; $t\left(V_{\max }\right)$ is the initial time, at which the voltage has its maximal value and the discharge starts; and $t\left(V_{\min }\right)$ is the final time, at which the discharge finishes (i.e., $V=0$ ). Furthermore, for the symmetric $\mathrm{SC}$, the capacitance of a single electrode according to the literature [55] is

$$
C_{\text {electrode }}=4 \times C_{\text {total }}
$$

Based on the equations above, the areal capacitances deduced from $\mathrm{CV}$ for the single PET/Cu/C/rGO-PC and PET/GrI/ rGO-PC electrodes were found to be $\sim 0.58$ and $0.19 \mathrm{mF} / \mathrm{cm}^{2}$ at $100 \mathrm{mV} / \mathrm{s}$, respectively. The corresponding gravimetric capacitance is $0.83 \mathrm{~F} / \mathrm{g}$ and $0.27 \mathrm{~F} / \mathrm{g}$, respectively. At the same time, the areal capacitances deduced from GCD are 0.93 and $0.25 \mathrm{mF} / \mathrm{cm}^{2}$ at $10 \mu \mathrm{A} / \mathrm{cm}^{2}$, respectively.

Table 1 summarizes the results of this work in comparison with the literature reports on similar rGO-based systems [56-60]. Romero et al. reported that the areal capacitance of $0.23 \mathrm{mF} / \mathrm{cm}^{2}$ at $10 \mathrm{mV} / \mathrm{s}$ for infrared $\mathrm{CO}_{2}$ laser-induced graphene materials from Kapton ${ }^{\circledR} \mathrm{HN}$ polyimide films was higher than that of $0.16 \mathrm{mF} / \mathrm{cm}^{2}$ for $\mathrm{rGO}$ obtained 
on PET by UV laser [56]. The rGO layers obtained through thermal treatment at $850{ }^{\circ} \mathrm{C}$ demonstrated an areal capacitance of $\sim 2.2 \mathrm{mF} / \mathrm{cm}^{2}$ at $25 \mathrm{mV} / \mathrm{s}$ as can be seen in the work by Ghasemi et al. [57]. The areal capacitance of $3.51 \mathrm{mF} / \mathrm{cm}^{2}$ was reported by Chen et al. for an electrode fabricated by immersion of the carbon cloth into GO solution with further heat treatment [58]. Beidaghi et al. calculated $\sim 3 \mathrm{mF} / \mathrm{cm}^{2}$ capacitance for $\mathrm{rGO}$ interdigital electrodes prepared by electrostatic spray deposition and photolithography liftoff methods [59]. Vacuum-filtrated rGO freestanding films that were chemically reduced by hydrazine hydrate were prepared by Xu et al., and an areal capacitance of $\sim 100 \mathrm{mF} / \mathrm{cm}^{2}$ was reported at $0.2 \mathrm{~mA} / \mathrm{cm}^{2}$, although it rapidly decreased with the current density increasing to $\sim 10 \mathrm{mF} / \mathrm{cm}^{2}$ at $10 \mathrm{~mA} / \mathrm{cm}^{2}$ [60]. Moreover, such a decrease, as well as the poor electrical conductivity of the pure rGO film electrode, was ascribed to its compact lamellar structure in the process of vacuum extraction, which could prevent the transmission of electrolyte ions to some extent [60]. As can be seen from Table 1, the obtained values of the areal capacitance for both SCs in the current work are slightly lower than the reported ones for graphene and rGO without $\mathrm{PC}$, thus indicating that the addition of PC does not enhance electrode performance, although the rGO-PC electrodes are applicable to a flexible SC. However, the areal capacitance of rGO papers prepared by vacuum filtration was reported by Zhu et al. to strongly increase with the thickness [61] that can be used for the further study of the current materials.

Table 1. The literature data for areal capacitance of rGO-based SC electrodes for comparison with the results of this work.

\begin{tabular}{|c|c|c|c|}
\hline Electrode & Electrolyte & Area Capacitance & Reference \\
\hline $\begin{array}{c}\text { rGO-PC, vacuum } \\
\text { filtration, } \\
\text { placed on } \mathrm{PET} / \mathrm{Cu} / \mathrm{C}\end{array}$ & $\mathrm{NaCl}$ & $0.93 \mathrm{mF} / \mathrm{cm}^{2}$ at $10 \mu \mathrm{A} / \mathrm{cm}^{2}$ & This work \\
\hline $\begin{array}{l}\text { rGO-PC, vacuum } \\
\text { filtration, } \\
\text { placed on PET/GrI }\end{array}$ & $\mathrm{NaCl}$ & $0.25 \mathrm{mF} / \mathrm{cm}^{2}$ at $10 \mu \mathrm{A} / \mathrm{cm}^{2}$ & This work \\
\hline $\begin{array}{l}\text { Graphene, laser } \\
\text { synthetized on } \\
\text { Kapton }\end{array}$ & $\mathrm{H}_{3} \mathrm{PO}_{4}$-PVA & $0.23 \mathrm{mF} / \mathrm{cm}^{2}$ at $10 \mathrm{mV} / \mathrm{s}$ & [56] \\
\hline $\begin{array}{l}\text { rGO, placed on } \mathrm{Si} \\
\text { substrate }\end{array}$ & $\mathrm{KCl}$ & $\sim 2.2 \mathrm{mF} / \mathrm{cm}^{2}$ at $25 \mathrm{mV} / \mathrm{s}$ & [57] \\
\hline $\begin{array}{l}\text { rGO, covered on } \\
\text { carbon cloth }\end{array}$ & $\mathrm{H}_{2} \mathrm{SO}_{4}$ & $3.5 \mathrm{mF} / \mathrm{cm}^{2}$ at $0.5 \mathrm{~mA} / \mathrm{cm}^{2}$ & [58] \\
\hline $\begin{array}{c}\text { rGO, interdigital } \\
\text { microelectrode arrays }\end{array}$ & $\mathrm{KCl}$ & $3 \mathrm{mF} / \mathrm{cm}^{2}$ & [59] \\
\hline $\begin{array}{l}\text { rGO, vacuum } \\
\text { filtration }\end{array}$ & $\mathrm{H}_{2} \mathrm{SO}_{4}$-PVA & $\sim 10 \mathrm{mF} / \mathrm{cm}^{2}$ at $10 \mathrm{~mA} / \mathrm{cm}^{2}$ & [60] \\
\hline
\end{tabular}

\section{Conclusions}

In the current work, self-supported rGO paper with polycarbonate was prepared by simple vacuum filtration and low-temperature annealing. $\mathrm{rGO}-\mathrm{PC}$ as a freestanding single electrode was studied in a three-electrode system and represented a capacitive energy storage mechanism. To fabricate flexible supercapacitors, inexpensive PET/Cu/C and PET/GrI were prepared by the facile method and used as flexible supports for the rGO-PC electrode active material. Fabricated flexible symmetric supercapacitors based on rGO-PC have shown similar behavior with a higher areal capacitance value than that on PET/Cu/C substrate. Improved electrochemical results are expected in further work by modifying the thickness and surface of the active material and by using an electrolyte with a wider potential window. 
Author Contributions: Conceptualization, data curation and writing-original draft preparation, O.O.; methodology, O.O., A.C.B. and S.T.; validation, O.O., A.C.B. and S.T.; formal analysis, A.T., A.C.B., S.T. and K.A.; resources, O.O., A.C.B. and S.T.; writing-review and editing, A.T. All authors have read and agreed to the published version of the manuscript.

Funding: This article is funded by national funds, through FCT-Fundacao para a Ciencia e a Tecnologia, in the scope of the framework contract foreseen in numbers 4, 5 and 6 of article 23 of the Decree Law 57/2016, of 29 August and UIDB/00481/2020 and UIDP/00481/2020, and CENTRO-010145-FEDER-022083-Centro Portugal Regional Operational Programme (Centro2020), under the PORTUGAL 2020 Partnership Agreement, through the European Regional Development Fund. Olena Okhay acknowledges the European Consortium of Innovative Universities (ECIU) for its support with a research mobility grant to the University of Tampere. Alexander Tkach acknowledges the project CICECO Aveiro Institute of Materials (UIDB/50011/2020 and UIDP/50011/2020), financed by national funds through the FCT/MCTES and, when appropriate, co-financed by FEDER under the PT2020 Partnership Agreement.

Institutional Review Board Statement: Not applicable.

Informed Consent Statement: Not applicable.

Data Availability Statement: The data presented in this study are available on request from the corresponding author.

Acknowledgments: The authors acknowledge Jari Keskinen from Tampere University for his valuable contribution to the electrochemical measurements.

Conflicts of Interest: The authors declare no conflict of interest.

\section{References}

1. Brodie, B.C. On the Atomic Weight of Graphite. Philos. Trans. R. Soc. Lond. 1859, 149, 249-259. [CrossRef]

2. Kohlschütter, V.; Haenni, P. Zur Kenntnis des Graphitischen Kohlenstoffs und der Graphitsäure. Z. Anorg. Allg. Chem. 1918, 105, 121-144. [CrossRef]

3. Wallace, P.R. The band theory of graphite. Phys. Rev. 1947, 71, 622-634. [CrossRef]

4. Ruess, G.; Vogt, F. Höchstlamellarer Kohlenstoff aus Graphitoxyhydroxyd. Monatsh. Chem. 1948, 78, 222-242. [CrossRef]

5. Boehm, H.P.; Setton, R.; Stumpp, E. Nomenclature and terminology of graphite intercalation compounds. Carbon 1986, $24,241$. [CrossRef]

6. Novoselov, K.S.; Geim, A.K.; Morozov, S.V.; Jiang, D.; Zhang, Y.; Dubonos, S.V.; Grigorieva, I.V.; Firsov, A.A. Electric field effect in atomically thin carbon films. Science 2004, 306, 666. [CrossRef]

7. Novoselov, K.S.; Geim, A.K.; Morozov, S.V.; Jiang, D.; Katsnelson, M.I.; Grigorieva, I.V.; Dubonos, S.V.; Firsov, A.A. Twodimensional gas of massless Dirac fermions in graphene. Nature 2005, 438, 197-200. [CrossRef] [PubMed]

8. Zhang, Y.B.; Tan, Y.W.; Stormer, H.L.; Kim, P. Experimental observation of the quantum Hall effect and Berry's phase in graphene. Nature 2005, 438, 201-204. [CrossRef] [PubMed]

9. Züttel, A.; Sudan, P.; Mauron, P.; Wenger, P. Model for the hydrogen adsorption on carbon nanostructures. Appl. Phys. A 2004, 78, 941-946. [CrossRef]

10. Sundaram, R.S. Chemically derived graphene. In Graphene: Properties, Preparation, Characterisation and Devices; Skakalova, V., Kaiser, A.B., Eds.; Woodhead Publishing: Sawston, UK, 2014; pp. 50-80. [CrossRef]

11. Okhay, O.; Tkach, A.; Hortiguela Gallo, M.J.; Otero-Irurueta, G.; Mikhalev, S.; Staitic, P.; Lufrano, F. Energy storage of supercapacitor electrodes on carbon cloth enhanced by graphene oxide aerogel reducing conditions. J. Energy Storage 2020, $32,101839$. [CrossRef]

12. Sengupta, I.; Chakraborty, S.; Talukdar, M.; Pal, S.K.; Chakraborty, S. Thermal reduction of graphene oxide: How temperature influences purity. J. Mater. Res. 2018, 33, 4113. [CrossRef]

13. Ganguly, A.; Sharma, S.; Papakonstantinou, P.; Hamilton, J. Probing the Thermal Deoxygenation of Graphene Oxide Using High-Resolution In situ X-ray-Based Spectroscopies. J. Phys. Chem. C 2011, 115, 17009-17019. [CrossRef]

14. Ramamoorthy, H.; Buapan, K.; Chiawchan, T.; Thamkrongart, K.; Somphonsane, R. Exploration of the temperature-dependent correlations present in the structural, morphological and electrical properties of thermally reduced free-standing graphene oxide papers. J. Mater. Sci. 2021, 56, 15134-15150. [CrossRef]

15. Tamboli, S.H.; Seok Kim, B.; Choi, G.; Lee, H.; Lee, D.; Patil, U.M.; Lim, J.; Kulkarni, S.B.; Chan Jun, S.; Hee Cho, H. Post-heating effects on the physical and electrochemical capacitive properties of reduced graphene oxide paper. Mater. Chem. A 2014, 2, 5077. [CrossRef]

16. Karthick, R.; Brindha, M.; Selvaraj, M.; Ramu, S. Stable colloidal dispersion of functionalized reduced graphene oxide in aqueous medium for transparent conductive film. J. Colloid Interface Sci. 2013, 406, 69-74. [CrossRef] [PubMed] 
17. Tarcan, R.; Todor-Boer, O.; Petrovai, I.; Leordean, C.; Astilean, S.; Botiz, I. Reduced graphene oxide today. J. Mater. Chem. C 2020, 8, 1198-1224. [CrossRef]

18. Liu, C.; Yu, Z.; Neff, D.; Zhamu, A.; Jang, B.Z. Graphene-based supercapacitor with an ultrahigh energy density. Nano Lett. 2010, 10, 4863-4868. [CrossRef]

19. El-Kady, M.F.; Strong, V.; Dubin, S.; Kaner, R.B. Laser scribing of high-performance and flexible graphene-based electrochemical capacitors. Science 2012, 335, 1326-1330. [CrossRef]

20. El-Kady, M.; Shao, Y.; Kaner, R. Graphene for batteries, supercapacitors and beyond. Nat. Rev. Mater. 2016, 1, 16033. [CrossRef]

21. Ke, Q.; Wang, J. Graphene-based materials for supercapacitor electrodes-A review. J. Mater. 2016, 2, 37-54. [CrossRef]

22. Lemine, A.S.; Zagho, M.M.; Altahtamouni, T.M.; Bensalah, N. Graphene a promising electrode material for supercapacitors-A review. Int. J. Energy Res. 2018, 42, 4284-4300. [CrossRef]

23. Zuliani, J.E.; Tong, S.; Jia, C.Q.; Kirk, D.W. Contribution of surface oxygen groups to the measured capacitance of porous carbon supercapacitors. J. Power Sources 2018, 395, 271-279. [CrossRef]

24. Li, J.; Tang, J.; Yuan, J.; Zhang, K.; Yu, X.; Sun, Y.; Zhang, H.; Qin, L.-C. Porous carbon nanotube/graphene composites for high-performance supercapacitors. Chem. Phys. Lett. 2018, 693, 60-65. [CrossRef]

25. Huang, Z.-D.; Zhang, B.; Liang, R.; Zheng, Q.-B.; Oh, S.W.; Lin, X.Y.; Yousefi, N.; Kim, J.K. Effects of reduction process and carbon nanotube content on the supercapacitive performance of flexible graphene oxide papers. Carbon 2012, 50, 4239-4251. [CrossRef]

26. Alazmi, A.; El Tall, O.; Rasul, S.; Hedhili, M.N.; Patole, S.P.; Costa, P.M.F.J. A process to enhance the specific surface area and capacitance of hydrothermally reduced graphene oxide. Nanoscale 2016, 8, 17782-17787. [CrossRef]

27. Dubal, D.P.; Kim, J.G.; Kim, Y.; Holze, R.; Lokhande, C.D.; Kim, W.B. Supercapacitors based on flexible substrates: An overview. Energy Technol. 2014, 2, 325-341. [CrossRef]

28. Faruque, M.A.A.; Syduzzaman, M.; Sarkar, J.; Bilisik, K.; Naebe, M. A review on the production methods and applications of graphene materials. Nanomaterials 2021, 11, 2414. [CrossRef]

29. Li, L.; Zhang, D.; Deng, J.; Fang, J.; Gou, Y. Review-Preparation and application of graphene-based hybrid materials through electrochemical exfoliation. J. Electrochem. Soc. 2020, 167, 086511. [CrossRef]

30. Liu, S.; Hu, K.; Cerruti, M.; Barthelat, F. Ultra-stiff graphene oxide paper prepared by directed-flow vacuum filtration. Carbon 2020, 158, 426-434. [CrossRef]

31. Zhao, S.; Li, M.; Wu, X.; Yu, S.H.; Zhang, W.; Luo, J.; Wang, J.; Geng, Y.; Gou, Q.; Sun, K. Graphene-based free-standing bendable films: Designs, fabrications, and applications. Mater. Today Adv. 2020, 6, 100060. [CrossRef]

32. Li, Z.; Chen, X.; Zhang, C.; Baer, E.; Langhe, D.; Ponting, M.; Zhu, L. High dielectric constant polycarbonate/nylon multilayer films capacitors with self-healing capability. ACS Appl. Polym. Mater. 2019, 1, 867-875. [CrossRef]

33. Legrand, G.D.; Bendler, G.T. Handbook of Polycarbonate Science and Technology; CRC Press: Boca Raton, FL, USA, 1999.

34. Singh, J.; Bansal, S.A.; Singh, A.P. Mechanical Characterization of Polycarbonate-Graphene Oxide (PCG) Nanocomposite. In Advances in Production and Industrial Engineering; Pandey, M., Ed.; Springer Nature Singapore Pte Ltd.: Singapore, 2021; pp. 103-111. [CrossRef]

35. Yoon, S.-H.; Jung, H.-T. Grafting polycarbonate onto graphene nanosheets: Synthesis and characterization of high performance polycarbonate-graphene nanocomposites for ESD/EMI applications. RSC Adv. 2017, 7, 45902-45910. [CrossRef]

36. Li, D.; Del Rio Castillo, A.E.; Jussila, H.; Ye, G.; Ren, Z.; Bai, J.; Chen, X.; Lipsanen, H.; Sun, Z.; Bonaccorso, F. Black phosphorus polycarbonate polymer composite for pulsed fibre lasers. Appl. Mater. Today 2016, 4, 17-23. [CrossRef]

37. Sasaki, H.; Hamanaka, I.; Takahashi, Y.; Kawaguchi, T. Effect of reinforcement on the flexural properties of injection-molded thermoplastic denture base resins. J. Prosthodont. 2015, 26, 302-308. [CrossRef]

38. Lago, E.; Toth, P.S.; Pugliese, G.; Pellegrini, V.; Bonaccorso, F. Solution blending preparation of polycarbonate/graphene composite: Boosting the mechanical and electrical properties. RSC Adv. 2016, 6, 97931-97940. [CrossRef]

39. Leeladhar, P.; Raturi, J.P. Singh. Sunlight-driven eco-friendly smart curtain based on infrared responsive graphene oxide-polymer photoactuators. Sci. Rep. 2018, 8, 3687. [CrossRef]

40. Yadav, A.; Kumar Yadav, D.; Kumar Mishra, J.; Sahu, R.; Jain, S.K.; Dixit, S.; Agarwal, G.; Jakhar, N.; Tripath, B. Effect of BaTiO 3 Nanofillers on the Energy Storage Performance of Polymer Nanocomposites. Macromol. Symp. 2021, 399, 2100024. [CrossRef]

41. Rogal'skii, S.P.; Pud, A.A.; Shapoval, G.S.; Mel'nik, A.F.; Bryk, M.T. Nature of Initiators for Indirect Electrochemical Reductive Degradation of Polycarbonates in Dimethylformamide. Theor. Exp. Chem. 2004, 40, 33-38. [CrossRef]

42. Zhu, D.; Hou, J.; Zhang, L.; Gao, Y.; Dai, B.; Lian, Y.; Yan, H.; Zhang, H. Microbial Porous Carbon by Low-Alkali Activation for Flexible Supercapacitors. J. Electron. Mater. 2021, 50, 6733-6740. [CrossRef]

43. Wu, Y.; Yan, M.; Sun, L.; Shi, W. Flexible yolk-shelled $\mathrm{NiCo}_{2} \mathrm{~S}_{4}$ hollow spheres/RGO film electrodes for efficient supercapacitive energy storage. New J. Chem. 2018, 42, 16174-16182. [CrossRef]

44. Saito, K.; Jehanno, C.; Meabe, L.; Olmedo-Martínez, J.L.; Mecerreyes, D.; Fukushima, K.; Sardon, H. From plastic waste to polymer electrolytes for batteries through chemical upcycling of polycarbonate. J. Mater. Chem. A 2020, 8, 13921-13926. [CrossRef]

45. Matsumoto, M.; Uno, T.; Kubo, M.; Itoh, T. Polymer electrolytes based on polycarbonates and their electrochemical and thermal properties. Ionics 2013, 19, 615-622. [CrossRef]

46. Farzana, R.; Rajarao, R.; Bhat, B.R.; Sahajwalla, V. Performance of an activated carbon supercapacitor electrode synthesised from waste Compact Discs (CDs). J. Ind. Eng. Chem. 2018, 65, 387-396. [CrossRef] 
47. Okhay, O.; Gonçalves, G.; Dias, C.; Ventura, J.; Vieira, E.M.F.; Gonçalves, L.M.V.; Tkach, A. Tuning electrical and thermoelectric properties of freestanding graphene oxide papers by carbon nanotubes and heat treatment. J. Alloys Compd. 2019, 781, 196-200. [CrossRef]

48. Pell, W.; Conway, B.; Marincic, N. Analysis of non-uniform charge/discharge and rate effects in porous carbon capacitors containing sub-optimal electrolyte concentrations. J. Electroanal. Chem. 2000, 491, 9-21. [CrossRef]

49. IEC-62391-2. Fixed Electric Double Layer Capacitors for Use in Electronic Equipment-Part 2: Sectional Specification-Electric Double Layer Capacitors Fpr Power Application, 1st ed. International Standard, International Electrochemical Commission, ICS Codes 31.060.10. Available online: https://webstore.iec.ch/preview/info_iec62391-1\%7Bed1.0\%7Den.pdf (accessed on 10 April 2006).

50. Mathis, T.S.; Kurra, N.; Wang, X.; Pinto, D.; Simon, P.; Gogotsi, Y. Energy storage data reporting in perspective-guidelines for interpreting the performance of electrochemical energy storage systems. Adv. Energy Mater. 2019, 9, 1902007. [CrossRef]

51. Gogotsi, Y.; Penner, R.M. Energy storage in nanomaterials-capacitive, pseudocapacitive, or battery-like? ACS Nano 2018, 12, 2081-2083. [CrossRef] [PubMed]

52. Okhay, O.; Tkach, A. Graphene/reduced graphene oxide-carbon nanotubes composite electrodes: From capacitive to battery-type behaviour. Nanomaterials 2021, 11, 1240. [CrossRef] [PubMed]

53. Paleo, A.J.; Staiti, P.; Rocha, A.M.; Squadrito, G.; Lufrano, F. Lifetime assessment of solid-state hybrid supercapacitors based on cotton fabric electrodes. J. Power Sources 2019, 434, 226735. [CrossRef]

54. Park, H.; Ambade, R.B.; Noh, S.H.; Eom, W.; Koh, K.H.; Ambade, S.B.; Lee, W.J.; Kim, S.H.; Han, T.H. Porous graphene-carbon nanotube scaffolds for fiber supercapacitors. ACS Appl. Mater. Interfaces 2019, 11, 9011-9022. [CrossRef]

55. Tuukkanen, S.; Krebs, M. Printable power storage: Batteries and supercapacitors. In Organic and Printed Electronics, 1st ed.; Nisato, G., Lupo, D., Ganz, S., Eds.; Jenny Stanford Publishing: New York, NY, USA, 2016; pp. 265-291.

56. Romero, F.J.; Gerardo, D.; Romero, R.; Ortiz-Gomez, I.; Salinas-Castillo, A.; Moraila-Martinez, C.L.; Rodriguez, N.; Morales, D.P. Comparison of laser-synthetized nanographene-based electrodes for flexible supercapacitors. Micromachines 2020, 11, 555. [CrossRef] [PubMed]

57. Ghasemi, F.; Jalali, M.; Abdollahi, A.; Mohammadi, S.; Sanaee, Z.; Mohajerzadeh, S. A high performance supercapacitor based on decoration of $\mathrm{MoS}_{2}$ /reduced graphene oxide with $\mathrm{NiO}$ nanoparticles. RSC Adv. 2017, 7, 52772. [CrossRef]

58. Chen, Y.; Bai, J.; Yang, D.; Sun, P.; Li, X. Excellent performance of flexible supercapacitor based on the ternary composites of reduced graphene oxide/molybdenum disulfide/poly (3,4-ethylenedioxythiophene). Electrochim. Acta 2020, $330,135205$. [CrossRef]

59. Beidaghi, M.; Wang, C. Micro-supercapacitors based on interdigital electrodes of reduced graphene oxide and carbon nanotube composites with ultrahigh power handling performance. Adv. Funct. Mater. 2012, 22, 4501-4510. [CrossRef]

60. Xu, L.; Li, Y.; Jia, M.; Zhao, Q.; Jin, X.; Yao, C. Synthesis and characterization of free-standing activated carbon/reduced graphene oxide film electrodes for flexible supercapacitors. RSC Adv. 2017, 7, 45066-45074. [CrossRef]

61. Zhu, J.; Zu, J.; Liu, J.; Wang, Y.; Pei, M.; Xu, Y. Self-assembled reduced graphene oxide films with different thicknesses as high performance supercapacitor electrodes. J. Energy Storage 2020, 32, 101795. [CrossRef] 